\title{
Small Dose-Clonidine Prolongs Postoperative Analgesia after Sciatic- Femoral Nerve Block With 0.75\% Rovpivacaine for Foot Surgery
}

\author{
Anil Ratnawat ${ }^{1}$, Vijay Kumar ${ }^{1}$ \\ ${ }^{1}$ Assistant Professor, Department of Anaesthesia, Pacific Medical College and Hospital Udaipur, India.
}

\section{Abstract}

Background: Foot surgery is associated with severe pain that can extend significantly up to 48 hours and often requires large amounts of parenteral opioids. . The benefit of adding clonidine to LAs for peripheral nerve blocks is less clear, although it is widely believed that clonidine improves quality and duration of a LA block. The aim of this study was to evaluate the effects of adding $1 \mathrm{mg} / \mathrm{kg}$ clonidine to $0.75 \%$ ropivacaine during combined sciatic-femoral nerve block for hallux valgus repair. Subjects and Methods: Thirty six ASA physical status I and II patients, scheduled for elective hallux valgus repair under combined sciatic-femoral nerve block, were enrolled in the study. By using a sealed envelope technique, patients were randomly allocated to receive sciatic-femoral nerve block with $30 \mathrm{~mL}$ of either $0.75 \%$ ropivacaine alone (group Ropivacaine, $\mathrm{n} 5$ 15) or $0.75 \%$ ropivacaine plus $1 \mathrm{mg} / \mathrm{kg}$ clonidine (group Ropivacaine- Clonidine, $\mathrm{n} 5$ 15). Standard monitoring was used throughout the study, including noninvasive arterial blood pressure, heart rate, and pulse oximetry. The time from the end of anesthetic injection to resolution of motor block at the ankle of the operated foot and first request for postoperative analgesic was recorded. At discharge from the orthopedic ward and $3 \mathrm{wk}$ after hospital discharge, patients were also evaluated regarding the occurrence of neurological complications. Results: No differences in the time required to achieve surgical anesthesia were observed between patients receiving only $0.75 \%$ ropivacaine $(10[5-20] \mathrm{min})$ and those receiving the ropivacaine-clonidine mixture (10 [5-30] min). The mean time from block placement to first request for pain medication was shorter in group Ropivacaine than in group Ropivacaine- Clonidine $(\mathrm{P}=0.03$,. No differences in postoperative consumption of ketoprofen were observed between patients. Conclusion: Adding $1 \mathrm{mg} / \mathrm{kg}$ clonidine to $0.75 \%$ ropivacaine provided a 3-h delay in first request for pain medication after hallux valgus repair, with no clinically relevant side effects.

Keywords: Clonidine, Foot surgery, Femoral nerve block, Ropivacaine.

Corresponding Author: Dr. Vijay Kumar, 103, Teaching Quarters B, Pacific Medical College and Hospital Campus, Bhilon ka Bedla,, Udaipur-313001.

Received: May 2019

Accepted: June 2019

\section{Introduction}

Foot surgery is associated with severe pain that can extend significantly up to 48 hours and often requires large amounts of parenteral opioids. ${ }^{[1,2]}$ Sciatic nerve blockade reduces postoperative pain after major foot and ankle surgery with minimal side effects; ${ }^{[3]}$ however, the maximum duration of effective analgesia with long-acting local anesthetics after a single injection technique is only $8-24$ hours. ${ }^{[4]}$ Therefore, perineural catheters or local anesthetics in combination with adjuvants are often used in attempts to prolong the duration of a single-shot popliteal fossa block (SSPFB). ${ }^{[5,6]}$ Clonidine is a frequently used adjuvant to local anesthetics (LA). The analgesic properties of clonidine when administered intrathecally or epidurally have been demonstrated; they seem to be attributable to its $\alpha 2$ agonist properties. The benefit of adding clonidine to LAs for peripheral nerve blocks is less clear, although it is widely believed that clonidine improves quality and duration of a LA block. Hallux valgus repair is a minor surgical procedure, but it leads to significant pain in the postoperative period. For this reason, regional anesthesia with long-acting local anesthetics has been suggested. The injection of an a agonist along axons has been suggested to improve the nerve block characteristics of local anesthetic solutions through either a local vasoconstriction, a facilitation of $\mathrm{C}$ fiber blockade from the local anesthetic solution, or a spinal action caused by slow retrograde axonal transport or single diffusion along the nerve. Moreover, a2 receptors have been directly isolated on peripheral of the rat, ${ }^{[7]}$ whereas in clinical studies, the addition of clonidine to local anesthetic solutions improved peripheral nerve blocks by reducing the onset time, extending postoperative analgesia, and improving the efficacy of nerve block during surgery. ${ }^{[8-10]}$

Ropivacaine is a new long-acting local anesthetic with a favorable profile for peripheral nerve blocks when used at $0.75 \%$ or $1 \%$ concentrations. However, little is known about the interaction between small-dose clonidine and ropivacaine when used for peripheral nerve blocks.

The aim of this study was to evaluate the effects of adding 1 $\mathrm{mg} / \mathrm{kg}$ clonidine to $0.75 \%$ ropivacaine during combined 
sciatic-femoral nerve block for hallux valgus repair.

\section{Subjects and Methods}

Thirty six ASA physical status I and II patients, scheduled for elective hallux valgus repair under combined sciaticfemoral nerve block, were enrolled in the study. The study protocol was approved by our hospital ethical committee, and informed consent was obtained from each patient. Patients receiving chronic analgesic therapy, as well as those with contraindications to regional anesthesia, and having systemic diseases were excluded.

After an 18-gauge IV cannula had been inserted in the forearm, midazolam $0.05 \mathrm{mg} / \mathrm{kg}$ IV was given as premedication $10 \mathrm{~min}$ before block placement. Standard monitoring was used throughout the study, including noninvasive arterial blood pressure, heart rate, and pulse oximetry. The surgical procedure was always performed by using a standard thigh tourniquet inflated $100 \mathrm{~mm} \mathrm{Hg}$ higher than systolic arterial blood pressure. Hemodynamic variables were measured before block placement (Baseline) and every 5 min until the end of surgery. By using a sealed envelope technique, patients were randomly allocated to receive sciatic-femoral nerve block with $30 \mathrm{~mL}$ of either $0.75 \%$ ropivacaine alone (group Ropivacaine, n 5 15) or $0.75 \%$ ropivacaine plus $1 \mathrm{mg} / \mathrm{kg}$ clonidine (group RopivacaineClonidine, $\mathrm{n} 5 \mathrm{15}$ ). For the femoral block, $12 \mathrm{~mL}$ of anesthetic solution was used, and for the sciatic block, $18 \mathrm{~mL}$ of the same solution was used.

Nerve blocks were performed with the aid of a nerve stimulator by using a short-beveled, Teflon-coated stimulating needle. Stimulation frequency was set at $2 \mathrm{~Hz}$, while the intensity of stimulating current was initially set to deliver $1 \mathrm{~mA}$ and gradually decrease to, $0.5 \mathrm{~mA}$. Paresthesia was never intentionally sought. As routine at our department, a multiple-injection technique was used, eliciting specific muscular twitches on nerve stimulation to confirm exact needle location. First, we performed the femoral nerve block, which was immediately followed by the sciatic nerve block. For both femoral and sciatic nerve blocks, the total volume of anesthetic solution was equally divided among the acceptable twitches. Sensory and motor blocks on the operated limb were evaluated at 2, 5, 10, 20, and 30 min after the completion of anesthetic injection by an independent, blinded observer.

Further measurements were performed until surgical anesthesia was achieved. Sensory block was assessed by using the pinprick test, and motor block was evaluated by asking the patient to move the ankle against resistance and to elevate the leg with the hip passively flexed. At the same time, arterial blood pressure, heart rate, hemoglobin oxygen saturation, and degree of sedation were also recorded. The degree of sedation was evaluated by using the Observer's Assessment of Alertness/Sedation scale. [Table 1] Clinically relevant hypotension was treated with etilephrine ( $2 \mathrm{mg}$ IV), bradycardia was treated with atropine, and their occurrence was recorded.

The time to surgical blockade was defined as the time from the end of anesthetic injection to loss of pinprick sensation on sciatic and femoral nerves distribution with the inability to move the ankle and toes of the operated limb.
Postoperative analgesia consisted of ketoprofen, $100 \mathrm{mg}$ IV as required. Patients were given clear instruction for asking for a first postoperative analgesic as soon as they complained of discomfort caused by pain on the operated foot. When patients asked for the first postoperative pain medication, the degree of pain was measured by using a $100-\mathrm{mm}$ visual analog scale. The time from the end of anesthetic injection to resolution of motor block at the ankle of the operated foot and first request for postoperative analgesic was recorded. At discharge from the orthopedic ward and $3 \mathrm{wk}$ after hospital discharge, patients were also evaluated regarding the occurrence of neurological complications.

Statistical analysis:

The recorded data was compiled and entered in a spreadsheet computer program (Microsoft Excel 2007) and then exported to data editor page of SPSS version 15 (SPSS Inc., Chicago, Illinois, USA).

Descriptive statistics included computation of percentages, means and standard deviations. For all tests, confidence level and level of significance were set at $95 \%$ and $5 \%$ respectively.

\section{Results}

No differences in age in group Ropivacaine and in group Ropivacaine-Clonidine), weight $\mathrm{kg}$ in group Ropivacaine and $\mathrm{kg}$ in group Ropivacaine-Clonidine), height $\mathrm{cm}$ in group Ropivacaine and $165 \mathrm{~cm}$ in group Ropivacaine-Clonidine), male to female ratio ( 3 to 14 in group Ropivacaine and 4 to 13 in group Ropivacaine-Clonidine), and ASA physical status were observed between the two groups. Successful surgical anesthesia not requiring analgesic supplementation to complete surgery was reported in 14 patients in each group (.>.0.05 not significant).

No differences in the time required to achieve surgical anesthesia were observed between patients receiving only $0.75 \%$ ropivacaine $(10[5-20] \mathrm{min})$ and those receiving the ropivacaine-clonidine mixture (10 [5-30] $\mathrm{min})$.

Table 1: The Observer's Assessment of Alertness/Sedation Scoring System (OAA/S)

\begin{tabular}{|l|l|l|l|l|}
\hline Responsiveness & $\begin{array}{l}\text { Facial } \\
\text { expression }\end{array}$ & Eyes & Speech & $\begin{array}{l}\text { Score } \\
\text { level }\end{array}$ \\
\hline $\begin{array}{l}\text { Responds readily } \\
\text { to name spoken in } \\
\text { normal tone }\end{array}$ & Normal & $\begin{array}{l}\text { Clear, no } \\
\text { ptosis }\end{array}$ & Normal & 5 \\
\hline $\begin{array}{l}\text { Lethargic } \\
\text { response to name } \\
\text { spoken in } \\
\text { normal tone }\end{array}$ & $\begin{array}{l}\text { Mild } \\
\text { relaxation }\end{array}$ & $\begin{array}{l}\text { Glazed or } \\
\text { mild ptosis } \\
\text { (, half } \\
\text { the eye) }\end{array}$ & $\begin{array}{l}\text { Mild } \\
\text { slowing or } \\
\text { thickening }\end{array}$ & 4 \\
\hline $\begin{array}{l}\text { Responds only } \\
\text { after name is } \\
\text { called loudly } \\
\text { and/or repeatedly }\end{array}$ & $\begin{array}{l}\text { Marked } \\
\text { relaxation }\end{array}$ & $\begin{array}{l}\text { Glazed and } \\
\text { marked } \\
\text { ptosis } \\
\text { (\$half the } \\
\text { eye) }\end{array}$ & $\begin{array}{l}\text { Slurring or } \\
\text { prominent } \\
\text { Slowing }\end{array}$ & 3 \\
\hline $\begin{array}{l}\text { Responds only } \\
\text { after mild } \\
\text { prodding or } \\
\text { shaking }\end{array}$ & & $\begin{array}{l}\text { Few } \\
\text { recognizable } \\
\text { words }\end{array}$ & \\
\hline $\begin{array}{l}\text { Responds only } \\
\text { after squeezing } \\
\text { the trapezius }\end{array}$ & & & & \\
\hline
\end{tabular}

Ten minutes after block placement, patients in RopivacaineClonidine group were slightly more sedated than those 
0

patients receiving only $0.75 \%$ ropivacaine. However, no differences were observed at further assessments, and no clinically relevant decrease in oxygen saturation was observed in either group. No patient developed clinically relevant hypotensionor bradycardia as defined above, and no differences in arterial blood pressure and heart rate variables were observed between the two groups throughout the study. Resolution of motor block at the ankle of the operated foot required $10.5 \mathrm{~h}$ in patients receiving ropivacaine alone as compared with $15 \mathrm{~h}$ in those receiving the ropivacaineclonidine mixture $(\mathrm{P}=0.001)$. The degree of pain measured with the visual analog scale at the onset of postsurgical pain was similar in the two groups. The mean time from block placement to first request for pain medication was shorter in group Ropivacaine than in group Ropivacaine- Clonidine ( $\mathrm{P}$ $=0.03$. No differences in postoperative consumption of ketoprofen were observed between patients. Five patients in group Ropivacaine-Clonidine did not require postoperative pain medication during the first $24 \mathrm{~h}$ after surgery as compared with only one patient in group Ropivacaine; however, the observed difference was not statistically significant $(\mathrm{P}=0.17)$.

\section{Discussion}

Moderate to severe post-operative pain is associated following lower limb orthopaedic surgical procedures and tends to last longer than $24 \mathrm{~h}$, often resulting in immobility and a decrease in effective early mobilization. Therefore, it is important that effective post-operative pain management techniques should be used to decrease the incidence of the preventable post-operative complications. Peripheral nerve blocks have distinctly an edge over general anaesthesia and neuraxial blocks in this regard.Results of present study demonstrate that adding $1 \mathrm{mg} / \mathrm{kg}$ clonidine to $0.75 \%$ ropivacaine has no effect on onset time and quality of combined sciatic-femoral nerve block, but prolongs nerve block duration, providing a three-hour prolongation in postoperative pain relief, with only a mild, short-lived increase in the degree of sedation and no hemodynamic side effects. Bernard and Macarie8, evaluating the effects of adding 30 to $300 \mathrm{mg}$ clonidine to lidocaine for axillary brachial plexus anesthesia, reported that adding clonidine reduced block onset and improved the efficacy of surgical anesthesia. However, in agreement with our findings, other authors demonstrated that neither the onset nor the efficacy of nerve blockade was influenced by adding clonidine. These differences in the reported effects of smalldose clonidine on onset time and efficacy of nerve block may be explained by differences in the type of nerve block, mixture injected, and technique used to perform the block. In fact, a multipleinjection technique was used, which is known to improve both onset time and quality of nerve block, and this could have reduced the differences in onset time between the two groups. ${ }^{[9-14]}$

Duration of postoperative pain relief after sciaticfemoral nerve block performed with $0.75 \%$ ropivacaine alone is similar to findings reported in previous investigations, 2,3 whereas small doses clonidine provided a nearly $20 \%$ prolongation of postoperative analgesia. Clinical relevance of a three-hour delay in first request for postoperative pain medication might be questioned, because no differences in total ketoprofen consumption or in the number of patients not requesting postoperative analgesics were observed between the two groups. However, it should also be considered that the small size of the study prevents us from excluding a type two error when evaluating the number of patients not requesting postoperative analgesics during first 24 hours after surgery. Singelyn et al. ${ }^{[19]}$ suggested that $0.5 \mathrm{mg} / \mathrm{kg}$ clonidine should be recommended, because significant prolongation of analgesia was provided without inducing sedation, hypotension, or bradycardia. Larger doses of clonidine were used in our investigation, but only mild, and short-lasting increases in the degree of sedation were observed 10 minutes after block placement, and no relevant cardiovascular side effects were reported. This may be related to the different type of peripheral nerve block, probably influencing the rate of absorption of the injected anesthetic solutions. ${ }^{[15-20]}$

A control group receiving parenteral administration of the same dose of clonidine was not considered when designing our investigation; however, it has been widely demonstrated that subcutaneous or IM injection of clonidine was not as effective as the perineural administration, ${ }^{[21,22]}$ suggesting that the local anestheticprolonging effect of clonidine is probably mediated locally at the peripheral nerve. Even though injecting clonidine as the sole analgesic into the brachial plexus sheath did not provide clinically relevant analgesia, clonidine has been demonstrated to inhibit the action potential of $\mathrm{Aa}$ and $\mathrm{C}$ fibers in desheathed sciatic nerves. ${ }^{[23,24]}$ Inhibition of noradrenaline release, mediated by an interaction with a2- adrenergic presynaptic receptors, could be an alternative explanation for the enhancing effect of the peripheral administration of clonidine. ${ }^{[25]}$ Peripheral antinociception induced by clonidine has also been related to an a2-adrenoceptor mediated local release of enkephalinlike substance. ${ }^{[26]}$

Results of current study demonstrated that adding $1 \mathrm{mg} / \mathrm{kg}$ clonidine to $0.75 \%$ ropivacaine provided a three-hour delay in first analgesic request postoperatively, with only a light and short-lived increase in the degree of sedation and no hemodynamic adverse effects.

\section{Conclusion}

Adding $1 \mathrm{mg} / \mathrm{kg}$ clonidine to $0.75 \%$ ropivacaine provided a 3 $\mathrm{h}$ delay in first request for pain medication after hallux valgus repair, with no clinically relevant side effects.

\section{References}

1. Ong CK, Lirk P, Seymour RA, Jenkins BJ. The efficacy of preemptive analgesia for acute postoperative pain management: a meta-analysis. Anesth Analg. 2005;100(3):757-773.

2. Needoff M, Radford P, Costigan P. Local anesthesia for postoperative pain relief after foot surgery: a prospective clinical trial. Foot Ankle Int. 1995;16(1):11-13.

3. di Benedetto P, Casati A, Bertini L, Fanelli G, Chelly JE. Postoperative analgesia with continuous sciatic nerve block after foot surgery: a prospective, randomized comparison between the popliteal and subgluteal approaches. Anesth Analg. 2002;94(4):996-1000.

4. Cappelleri G, Aldegheri G, Ruggieri F, Mamo D, Fanelli G, Casati A. 
0

Minimum effective anesthetic concentration (MEAC) for sciatic nerve block: subgluteus and popliteal approaches. Can J Anaesth. 2007;54(4):283-289.

5. Cummings KC 3rd, Napierkowski DE, Parra-Sanchez I, et al. Effect of dexamethasone on the duration of interscalene nerve blocks with ropivacaine or bupivacaine. Br J Anaesth. 2011;107(3):446-453.

6. Paqueron X, Narchi P, Mazoit JX, Singelyn F, Benichou A, Macaire P. A randomized, observer-blinded determination of the median effective volume of local anesthetic required to anesthetize the sciatic nerve in the popliteal fossa for stimulating and nonstimulating perineural catheters. Reg Anesth Pain Med. 2009;34(4):290-295.

7. Khasar SG, Green PG, Chou B, Levine JD. Peripheral nociceptive effects of a2-adrenergic receptor agonist in the rat. Neuroscience 1995;66:427-32.

8. Bernard JM, Macarie P. Dose-range effects of clonidine added to lidocaine for brachial plexus block. Anesthesiology 1997;87: 277-84.

9. Maze M, Tranquilli W. Alpha-2 adrenoreceptor agonists: defining the role in clinical anesthesia. Anesthesiology 1991;74: 581-605.

10. Salonen MA, Kanto JH, Maze M. Clinical interactions with alpha-2 adrenergic agonists in anesthetic practice. J Clin Anesth 1992;4:164 72

11. Casati A, Fanelli G, Cappelleri GL, et al A clinical comparison of $0.75 \%$ ropivacaine, $1 \%$ ropivacaine or $0.5 \%$ bupivacaine for interscalene brachial plexus anaesthesia. Eur J Anaesth 1999;16: 784-9.

12. Browner WS, Black D, Newman B, Hulley SB. Estimating sample size and power. In: Hulley SB, Cummings SR, eds. Designing clinical research: an epidemiologic approach. Baltimore: Williams \& Wilkins, 1988:139-50.

13. Fanelli G. Peripheral nerve block with electric neurostimulation Minerva Anestesiol 1992;58:1025-6.

14. Fanelli G, Casati A, Garancini P, Torri G. Nerve stimulator and multiple injections technique for upper and lower limb blockade: failure rate patient acceptance and neurologic complications. Anesth Analg 1999;88:847-52

15. Chernik DA, Gilling SD, Laine $\mathrm{H}$, et al. Validity and reliability of the
Observer's Assessment of Alertness/Sedation scale: study with intravenous midazolam. J Clin Psycopharmacol 1990;10: 244-51.

16. Eledjam JJ, Deschodt J, Viel EJ, et al. Brachial plexus block with bupivacaine effects of added alpha-adrenergic agonists: comparison between clonidine and epinephrine. Can J Anaesth 1991;38:870 -5.

17. Lavoie J, Martin R, Tetrault JP, et al. Axillary plexus block using a peripheral nerve stimulator: single or multiple injections. Can J Anaesth 1992;39:583- 6 .

18. Casati A, Fanelli G, Beccaria P, et al. Effects of the single or multiple injection technique on the onset time of peripheral nerve blocks with 0.75\% ropivacaine. Anesth Analg 2000;91:181-4.

19. Singelyn FJ, Gouverneur JM, Robert A. A minimum dose of clonidine added to mepivacaine prolongs the duration of anesthesia and analgesia after axillary brachial plexus block. Anesth Analg 1996;83:1046 -50.

20. Agostoni M, Fanelli G, Nobili F, et al. Plasma levels of mepivacaine in the double block of the sciatic and femoral nerve. Minerva Anestesiol 1992:58:281-4.

21. Eisenach JC, De Kock M, Klimsha W. a2-Adrenergic agonists for regional anesthesia: a clinical review of clonidine. Anesthesiology 1996;85:655-74.

22. Tschernko EM, Klepetko H, Gruber E, et al. Clonidine added to the anesthetic solution enhances analgesia and improves oxygenation after intercostal nerve block for thoracotomy. Anesth Analg 1998;87:107-11.

23. Sia S, Lepri A. Clonidine administered as an axillary block does not affect postoperative pain when given as the sole analgesic. Anesth Analg 1999;88:1109-12.

24. Butterworth JF, Strichartz GR. The a2-adrenergic agonists clonidine and guanfacine produce tonic and phasic block of conduction in rat sciatic nerve fibers. Anesth Analg 1993;76: 295-301.

25. Gentili ME, Juhel A, Bonnet F. Peripheral analgesic effect of intraarticular clonidine. Pain 1996;64:593-6.

26. Nakamura M, Ferreira SH. Peripheral analgesic action of clonidine: medication by release of endogenous enkephalin-like substances. Eur J Pharmacol 1988;146:223-8.

Copyright: (c) the author(s), publisher. Academia Anesthesiologica Internationalis an Official Publication of "Society for Health Care \& Research Development". It is an open-access article distributed under the terms of the Creative Commons Attribution Non-Commercial License, which permits unrestricted non-commercial use, distribution, and reproduction in any medium, provided the original work is properly cited.

How to cite this article: Ratnawat A, Kumar V. Small Dose-Clonidine Prolongs Postoperative Analgesia after Sciatic-Femoral Nerve Block With 0.75\% Rovpivacaine for Foot Surgery. Acad. Anesthesiol. Int. 2019;4(2):17-20.

DOI: dx.doi.org/10.21276/aan.2019.4.2.5

Source of Support: Nil, Conflict of Interest: None declared. 